between TNF-alpha and ESR ( $\mathrm{p}<0,02)$, arthritis $(\mathrm{p}<0,01)$, capillaritis ( $p<0,01)$, lymphadenopathy $(\mathrm{p}<0,001)$; the negative correlation was observed with serum albumin $(\mathrm{p}<0,02)$ in females. The level of TNF-alpha was the low-positive in 2 pts $(4,5 \%)$, the moderate-positive in 8 pts $(18,1 \%)$, the high-positive in 26 pts $(59 \%)$ in males. There was a positive correlation between TNF-alpha and SLAM index ( $\mathrm{p}<0,01)$, SLEDAI $(\mathrm{p}<$ $0,06)$, antiphospholipid syndrome $(\mathrm{p}<0,01)$, IgG-anticardiolipin antibodies $(\mathrm{p}<0,03)$ in male group.

Conclusion There are differences between the level, the clinical value of TNF-alpha in male and female cohorts of pts with SLE. The measurement of TNF-alpha maybe a useful tool for monitoring disease activity, in the male cohort especially.

\section{AB0015 SYNOVIAL FLUID ANALYSIS: CORRELATION BETWEEN REAGENT STRIPS ANALYSIS AND WHITE BLOOD CELL COUNT}

S Aloui, H Ben Frej, S Chatti, I Hadda, I Bouajina, MH Abdessalem, T Chekir. Rheumatology, Farhat Hached Hospital, Sousse, Tunisia

\subsection{6/annrheumdis-2001.814}

\section{Background}

Objectives To determine if reagent test strips used to analyse inflammatory synovial fluid (SF) is as performing as white blood cell (WBC) count.

Methods 100 synovial fluid specimens obtained were tested using two techniques:

- reagent strips used to test urine (multistix 8SG

Bayerdiagnostics) to check the presence of leucocytes. An inflammatory SF was defined as a strip showing more than a trace for leucocytes. The analysis was performed by an investigator unaware of WBC count and of diagnosis.

- White blood cell count. An inflammatory SF was defined as WBC ${ }^{3} 2000$ cells $/ \mathrm{mm}^{3}$.

Specificity, sensitivity and like hood ratio (LR) of the reagent strip in diagnosing inflammatory SF were calculated.

Results 100 samples SF were tested. The performance of reagent strip were: sensitivity: $82 \%$ (IC: 95\%); specificity was $88 \%$ (IC: 95\%) LR: 5.6.

Conclusion Our study suggest that an evaluation of SF by reagent strips could be of interest to guide the diagnosis.

\section{OP0030 CARTILAGE DEGRADATION BY IL-18 IS PREDOMINANTLY MEDIATED BY IL-1 GENERATION}

LA Joosten, MA Helsen, LA Van den Bersselaar, E Lubberts, WB Van den Berg. Rheumatology Research Laboratory, UMC St-Radboud, Nijmegen, Netherlands

\subsection{6/annrheumdis-2001.815}

Background Interleukin-18 (IL-18) is a member of the IL-1 family of proteins that exerts proinflammatory effects. ${ }^{1}$ It was formally known as IGIF and is a pivotal cytokine for the development of Th1 responses. ${ }^{2}$ IL-18 is structurally related to IL- $1 \mathrm{~b}$ both cytokines need ICE or caspase- 1 for cleavage of the precursor to release the bioactive molecules. Apart from immune-stimulatory activity, IL-18 induces production of TNF and IL-1 in vitro. IL-18 synthesis is found in both articular chondrocytes and osteoblasts and, with respect to cartilage, IL-18 promotes gene expression of nitric oxide synthase, inducible cyclooxygenase, IL-6 and stromelysin.
Objectives The goal of the present study was to investigate whether IL-18 mediates cartilage degradation directly or via induction of other cytokines, such as IL-1 and IFN-g.

Methods Patellae of C57Bl/6, IL-1b deficient, Balb/C and IFN-g deficient mice were used for in vitro cartilage degradation experiments with either murine IL-18 or IL-1b. Patellar cartilage was pre-labelled with $35 \mathrm{~S}$-sulphate. The explants were cultured for $24 \mathrm{~h}, 48 \mathrm{~h}$ or $72 \mathrm{~h}$ in either IGF-1 (0.25 ug/ml), IGF-1/IL-18 (10 and $100 \mathrm{ng} / \mathrm{ml})$ or IGF-1/IL-1b (10 ng/ml). Patellae were washed in saline, fixed in $4 \%$ formaldehyde and subsequently decalcified in 5\% formic acid. Patellae were punched out of the adjacent tissue, dissolved and the $35 \mathrm{~S}$ content was measured by liquid scintillation counting. For IL-1 inhibition we added IL$1 \mathrm{Ra}(10 \mathrm{ug} / \mathrm{ml})$ or an ICE inhibitor $(2.5 \mathrm{uM})$ to the culture system.

Results IL-18 exposure for 24 or $48 \mathrm{~h}$ did not induce cartilage degradation, determined as release of prelabelled proteoglycans. Cartilage degradation by IL-18 was only found after a $72 \mathrm{~h}$ culture period In contrast, IL-1b did already induce marked cartilage degradation after $24 \mathrm{~h}$. To investigate whether generation of another destructive cytokine was responsible for the delay of cartilage degradation we added IL-1Ra or ICE inhibitors to the culture system. Blocking of IL-1 resulted in almost complete protection against IL-18 mediated cartilage degradation. Additionally, studies in IL-1b -/- mice showed that IL-1b was pivotal in IL-18-induced cartilage degradation. Since IL-18 is a potent inducer of IFN-g, we investigated whether IFN-g induction by IL-18 was involved. It was revealed that IL-18 mediated cartilage destruction was partly dependent on IFN-g induction.

Conclusion The present study demonstrated that IL-18 induces cartilage destruction in vitro. Here we showed that IL-1b generation, due to IL-18 exposure was essential for marked cartilage degradation. In addition, it was shown that induction of IFN-g was also involved in IL-18-induced cartilage degradation. These findings implicated that IL-18 contributed to cartilage destruction by induction of IL-1b and IFN-g. Inhibition of both IL-18 and IL- $1 \mathrm{~b}$ generation by ICE inhibitors might be a protective therapy in RA.

\section{REFERENCES}

1 Okamura $\mathrm{H}$, et al. Nature 1995;378:88

2 Akira S. Curr Opin Immunol. 2000;12:59

\section{OP0031 PROLONGED EXPOSURE OF T CELLS TO TNF DOWNREGULATES TCRZ AND EXPRESSION OF THE TCR/ CD3 COMPLEX}

${ }^{1} \mathrm{P}$ Isomäki, ${ }^{2} \mathrm{~N}$ Yasin, ${ }^{2} \mathrm{~A}$ Annenkov, ${ }^{2} \mathrm{~J}$ Clark, ${ }^{2} \mathrm{~B}$ Foxwell, ${ }^{2} \mathrm{Y}$ Chernajovsky, ${ }^{2} \mathrm{~A}$ Cope. ${ }^{1}$ Department of Medicine, Hämeenlinna Central Hospital, Hämeenlinna, Finland; ${ }^{2}$ The Kennedy Institute of Rheumatology Division, Imperial College School of Medicine, London, UK

\subsection{6/annrheumdis-2001.816}

Background A role for tumour necrosis factor $\alpha$ (TNF) in the pathogenesis of chronic inflammatory is now firmly established. Paradoxically, TNF also has potent immuno-modulatory effects on $\mathrm{CD}^{+} \mathrm{T}$ lymphocytes, since antigen specific proliferative and cytokine responses are suppressed following prolonged exposure to TNF. We studied whether TNF attenuated T cell activation by uncoupling proximal TCR signal transduction pathways using a mouse $\mathrm{T}$ cell hybridoma model. In this model, IL-2 production following peptide stimulation was suppressed by up to $90 \%$ by chronic TNF exposure, and was restored to control levels within 